\title{
A negative effect of Campylobacter capsule on bacterial interaction with an analogue of a host cell receptor
}

\author{
Sona Rubinchik, Alan M Seddon and Andrey V Karlyshev*
}

\begin{abstract}
Background: Campylobacter jejuni (C. jejuni) is the leading causative agent of bacterial gastrointestinal infections. The rise of antibiotic resistant forms of this pathogen necessitates the development of novel intervention strategies. One approach is the design of drugs preventing bacterial attachment to host cells. Although some putative C. jejuni adhesins have been identified, the molecular mechanisms of their interaction with host cells and their role in pathogenesis remain to be elucidated. C. jejuni adhesion may also be modulated by a bacterial capsule. However, the role of this structure in adhesion was not clear due to conflicting results published by different research groups. The aim of this study was to clarify the role of capsule in bacterial interaction with host cells by using an in vitro model of adhesion and an analogue of a host cell receptor.

Results: In this study, we developed an in vitro bacterial adhesion assay, which was validated using various tests, including competitive inhibition studies, exoglycosydase treatment and site-directed mutagenesis. We demonstrate that PEB3 is one of the cell surface glycoproteins required for bacterial interaction with an analogue of a host cell receptor. In contrast, JlpA glycoprotein adhesin is not required for such interaction. We demonstrate that the production of capsule reduces bacterial attachment, and that the genes involved in capsule and PEB3 adhesin biosynthesis are differentially regulated.

Conclusions: In this study we report an in vitro model for the investigation of bacterial interaction with analogs of host cell receptors. The results suggest an interfering effect of capsule on bacterial attachment. In addition, using a liquid culture, we demonstrate differential expression of a gene involved in capsule production (kpsM) and a gene encoding a glycoprotein adhesin (peb3). Further studies are required in order to establish if these genes are also differentially regulated during the infection process. The results will assist in better understanding of the mechanism of pathogenesis of $C$. jejuni in general and the role of capsule in the process in particular.
\end{abstract}

Keywords: Campylobacter, Adhesion, Attachment, Adhesins, Receptors, Glycoproteins, Glycosylation, MGL receptor, C-type receptor, Lectins

\section{Background}

Campylobacter jejuni (C. jejuni), a microaerophilic, spiralshaped, flagellated Gram-negative bacterium, is the most frequent cause of human gastroenteritis worldwide [1]. C. jejuni infections are often caused by consumption of undercooked poultry, unpasteurised milk or contaminated water [2]. Adhesion of C. jejuni to host cells plays

\footnotetext{
* Correspondence: a.karlyshev@kingston.ac.uk

School of Life Sciences, Kingston University, Faculty of Science, Engineering and Computing, Penrhyn Road, Kingston-upon Thames KT1 2EE, UK
}

an important role in colonisation of chickens and in human infection [3]. Campylobacter binding to host cell receptors is not mediated by fimbria or pili, like in $E$. coli and Salmonella [4]. As noted in a recent review, other bacterial cell structures may contribute to interaction of Campylobacter with host cells [5].

In some cases, bacterial adhesion can be mediated by oligosaccharides present on the surface of host cells $[6,7]$. In other cases, it is a pathogen oligosaccharide that is responsible for binding to specific, lectin-like, host cell structures. For example, a pathogenic Gram-positive 
bacterial species Nocardia rubra binds to a human lectin (intelectin) expressed by cells in different organs including intestine [8]. There is a possibility of similar lectin-glycan interactions between host cells and Campylobacter. For example, $C$. jejuni adhesion to Caco-2 cell receptors was inhibited by certain lectins [9].

Campylobacter is capable of producing a variety of glycoproteins, some of which are cell-surface located [10]. Inactivation of the $\mathrm{N}$-linked glycosylation system reduces bacterial ability to adhere to epithelial cells and thereby colonise the gastrointestinal tract $[11,12]$. These findings suggest a possible role of some bacterial cell surface surface-located bacterial N-linked glycoproteins in interaction with host cell receptors. Van Sorge and colleagues [13] demonstrated interaction of N-linked glycoproteins of $C$. jejuni with C-type lectins of Macrophage Galactosetype lectins (MGL). In similarity with other pathogens, the production of cell surface structures interacting with C-type lectins may assist $C$. jejuni in the evasion of the host immune response $[14,15]$.

Another cell surface structure that may affect bacterial interaction with host cell receptors is a capsular polysaccharide (CPS) [16-19]. Inactivation of the capsule production machinery in strain 81-176 led to a twofold decrease in adhesion to INT407 cells [20]. Similar findings were observed in another capsule deficient mutant, 81116/kpsE [21]. However, these data were not supported by complementation studies. Moreover, they are in disagreement with other studies where the absence of capsule showed increased adhesion of $C$. jejuni strain 11168 H to Caco- 2 cells [16]. The contradictory results may be a consequence of differences in assay conditions, bacterial strains and tissue cell lines.

In general, the capsules may play different roles in bacterial attachment. This depends on the nature of a bacterial pathogen, and on the structural features of the capsules and adhesins. For example, F1 capsule of a Yersinia pestis prevents fimbrial adhesins from interaction with host cell receptors [22], while production of a capsule by Neisseria meningitidis does not affect PilC1 adhesinmediated bacterial attachment [23].

In this study we developed and evaluated an in vitro ELISA-like assay for the investigation of $C$. jejuni interaction with host cell receptors. The assay was successfully used to study a role of capsule in attachment using SBA (Soya bean agglutinin) lectin as an analogue of a host cell receptor. In addition, using targeted mutagenesis (supported by complementation analysis) we investigated a role of PEB3 and JlpA adhesins in this interaction. Furthermore, using real time PCR, we found that peb3 and a capsule-related gene are differentially expressed. The results of these experiments suggest an interplay between bacterial capsule and adhesins in interaction with host cells.

\section{Results}

Dose-dependent specific binding of $C$. jejuni cells to immobilised SBA lectin

In order to investigate the mechanisms and factors involved in C. jejuni interaction with host cells, we developed an ELISA-like assay based on monitoring bacterial binding to immobilised analogues of host cell receptors. In this model we explored the idea that some N-link glycosylated proteins may be expressed on the bacterial cell surface, and may potentially play a role of adhesins. As glycan moieties in these glycoproteins contain terminal GalNAc residues recognised by SBA, we used the latter as an analogue of a host cell receptor.

Incubation of a suspension of C. jejuni $11168 \mathrm{H}$ cells with immobilised SBA resulted in bacterial attachment (Figure 1A). This binding was found to be specific as demonstrated by inhibitory effects by both GalNAc and a soluble form of SBA in a dose-dependent manner. The inhibitory effect was detectable with as low concentration of SBA lectin as $0.1 \mu \mathrm{M}$ (Figure 1B). GalNAc also showed an inhibitory effect at concentrations over $10 \mu \mathrm{M}$ (Figure 1C). Moreover, the bound cells could be detached in the presence of a soluble form of lectin or GalNAc (Figure 2). Further confirmation of specific binding was obtained by treatment of bacterial cells with an exoglycosidase. Removal of a terminal GalNAc resulted in a remarkable reduction of the ability of bacterial cells to attach (Figure 3).

In order to further confirm that the developed model of attachment is specific and is based on the surface-located GalNAc moieties, we repeated the binding experiments using $E$. coli cells carrying the entire $\mathrm{N}$-linked protein glycosylation apparatus ( $\mathrm{pgl}$ gene cluster) of $C$. jejuni [24]. Due to the absence of glycosylation acceptor proteins in strain E. coli XL2/pPGL1, the pgl system was found to be able to glycosylate the bacterial lipopolysaccharide, resulting in exposure of GalNAc residues on the cell surface [24] (Figure 4A). The results confirmed that $E$. coli XL2/pPGL1 cells are capable of binding to immobilized SBA lectin in a GalNAc dependent fashion (Figure 4B).

\section{Expression of PEB3 is required for binding of $C$. jejuni cells to immobilised SBA lectin}

Previous studies suggested a possible location of PEB3 protein on a bacterial cell surface [25,26]. The purified PEB3 protein was able to bind SBA lectin due to the presence of a GalNAc-containing glycan moiety [26]. In order to confirm that attachment of $C$. jejuni cells to immobilised SBA in our experiments is mediated by PEB3, we constructed and investigated the binding properties of the respective mutant. The results demonstrated significant

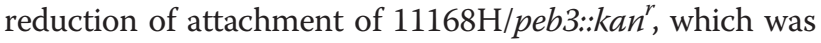
restored after complementation (Figure 5). 


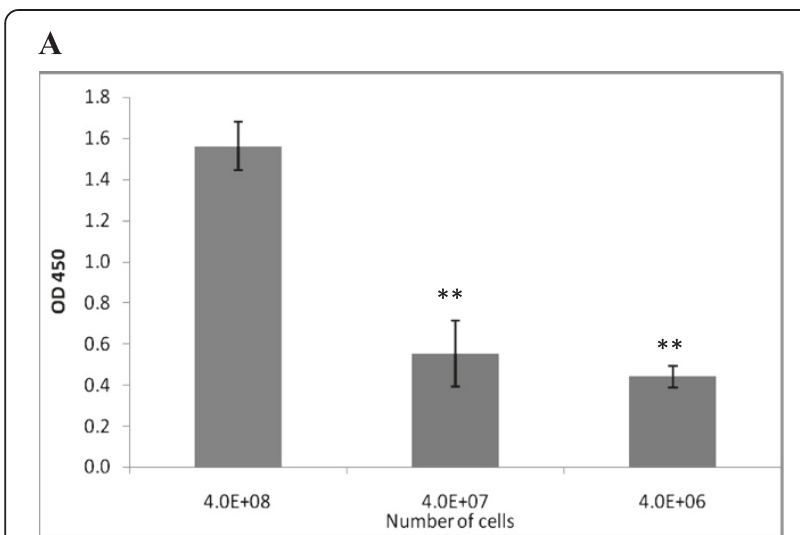

B

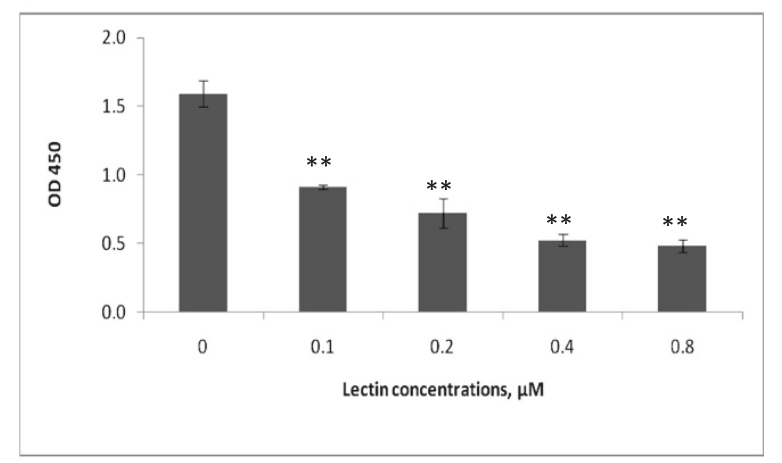

C

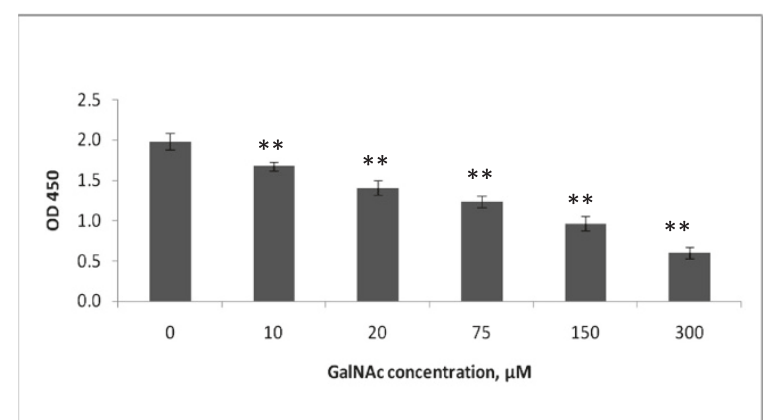

Figure 1 Interaction of $C$. jejuni with immobilised SBA. (A) C. jejuni $11168 \mathrm{H}$ interaction with SBA lectin is concentration dependent. The figures below the bars indicate the numbers of cells per well. (B) Effect of different concentrations of soluble SBA lectin on binding of $C$. jejuni $11168 \mathrm{H}$. (C) Effect of different concentrations of GalNAc on binding of C. jejuni $11168 \mathrm{H}$.

The results of this experiment also showed that peb3 mutation did not completely eliminate binding, suggesting that other glycoprotein(s) may be involved in specific interactions with this analogue of a host cell receptor. This hypothesis was supported by reduction of the residual binding of $11168 \mathrm{H} /$ peb3:: $\mathrm{kan}^{r}$ mutant in the presence of soluble lectin (Figure 5).

One of the other cell surface-located proteins of $C$. jejuni is JlpA, which was found to be an adhesin

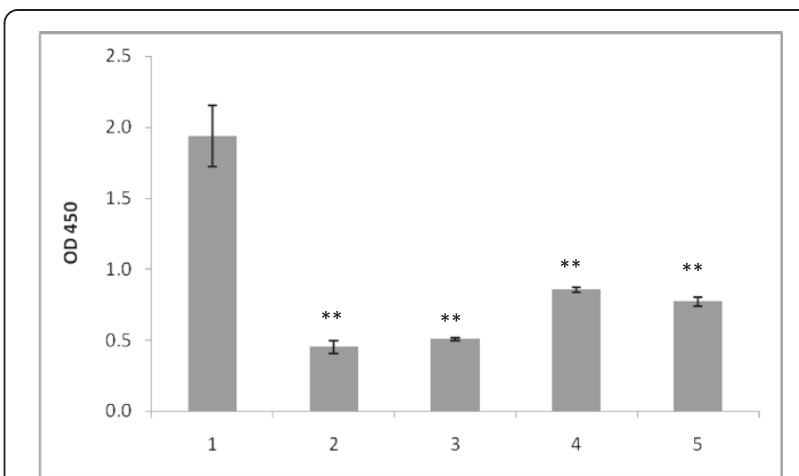

Figure 2 Detachment of cells of $C$. jejuni $11168 \mathrm{H}$ in the presence of $5 \mathrm{mM}$ and $10 \mathrm{mM}$ of soluble lectin ( 2 and 3 respectively), or $5 \mathrm{mM}$ and $10 \mathrm{mM}$ of GalNAc (4 and 5 respectively).

specifically binding to heat shock protein 90 [27]. As JlpA was also predicted to be an N-link glycosylated protein [28], there was a possibility that it might be responsible for residual binding of $11168 \mathrm{H} / \mathrm{peb3}:: \mathrm{kan}^{r}$ mutant. To verify this hypothesis, we constructed a $j l p A$ mutant and tested the effect of this mutation on attachment. Surprisingly, none of the three independent clonal isolates showed any difference when compared with the control recipient strain $11168 \mathrm{H}$ (data not shown) suggesting the presence of other GalNAc-containing adhesins.

\section{Production of capsule has a negative effect on binding}

The results shown in Figure 3 also have demonstrated a significantly higher efficiency of binding of the noncapsular mutant of strain $11168 \mathrm{H}$. These results, confirmed by analysis of three independent clonal isolates of this mutant (data not shown), revealed significant increase in binding upon inactivation of bacterial ability to produce capsule, suggesting an interfering effect

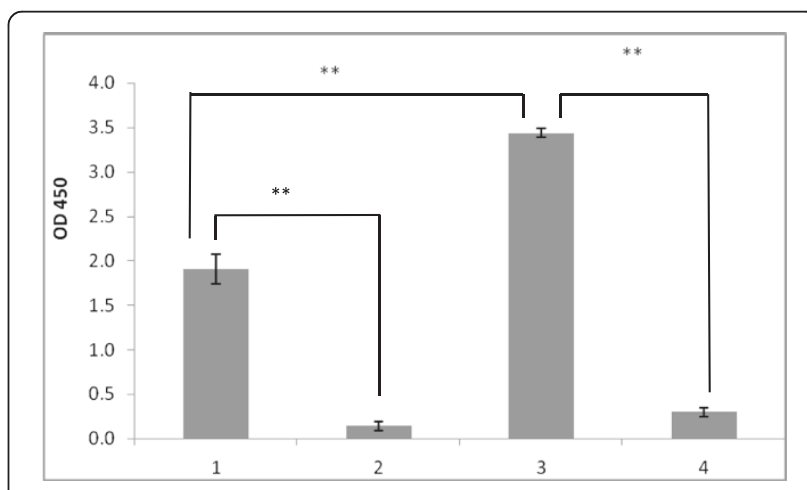

Figure 3 Reduction of binding upon treatment of bacteria with GalNAc-specific exoglycosydase. Results with C. jejuni $11168 \mathrm{H}$ strain

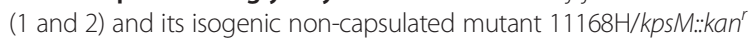
( 3 and 4 ) are presented. Samples before ( 1 and 3 ) and after ( 2 and 4$)$ treatment with exoglycosidase are shown. Elimination of capsule increases bacterial attachment (1 and 3). 

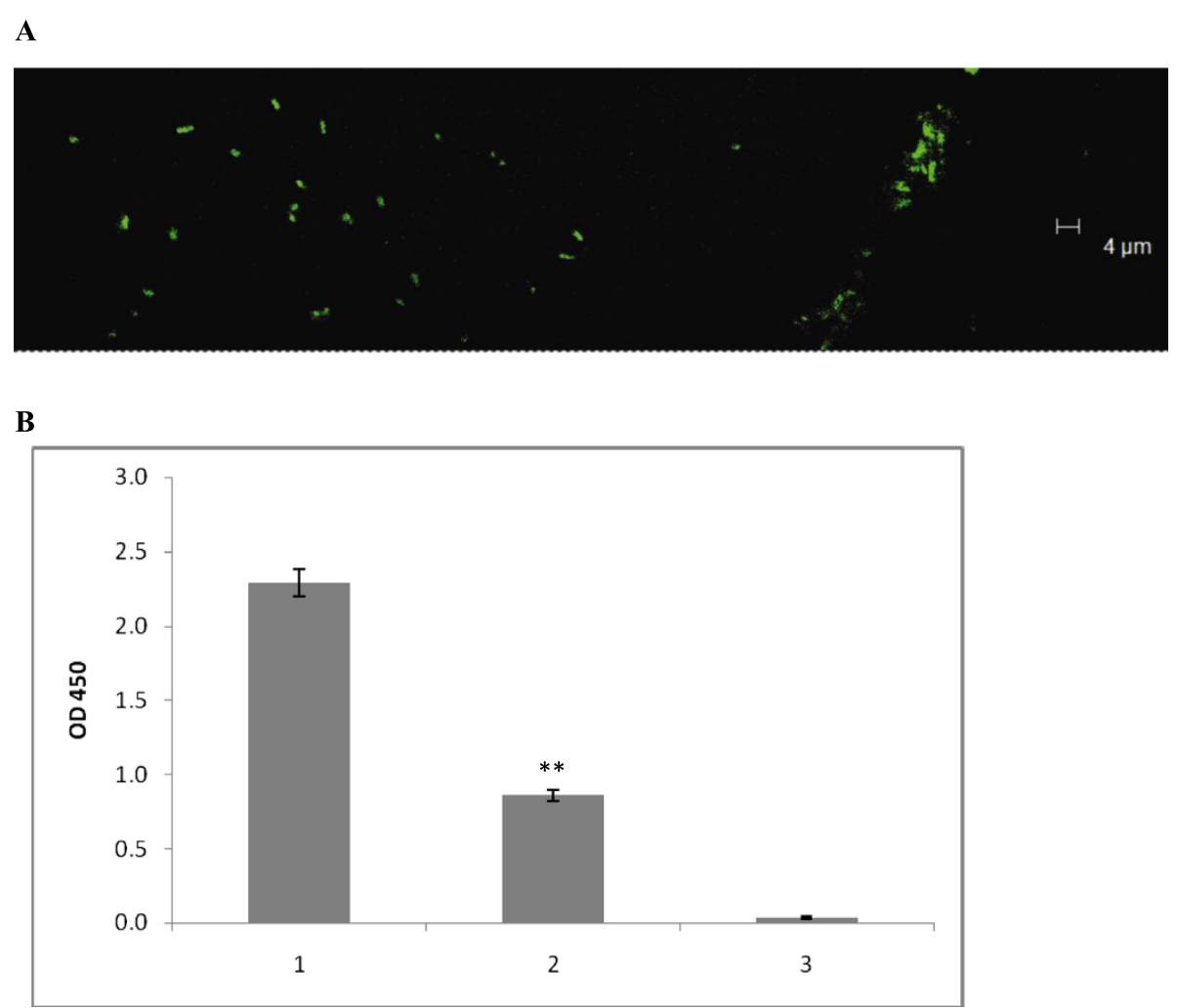

Figure 4 Interaction of $E$. coli cells, containing C. jejuni glycosylation gene cluster, with SBA lectin. (A) Confocal microscopy of E. coli XL2/ PPGL1 after treatment with fluorescently labelled SBA. No fluorescence was observed for E. coli XL2 control (data are not shown). (B) Attachment of E. coli XL2/PPGL1 to immobilized SBA lectin (1) is inhibited by GalNAc at $5 \mathrm{mM}$ (2). No binding of the recipient strain E. coli XL2 was detected (3).

of the later on the bacterial interaction with host cell receptors.

Peb3 and capsule-related genes are differentially expressed Due to antagonistic effects of capsule and PEB3 adhesin on bacterial attachment, we hypothesized that these structures might be differentially expressed. To test this

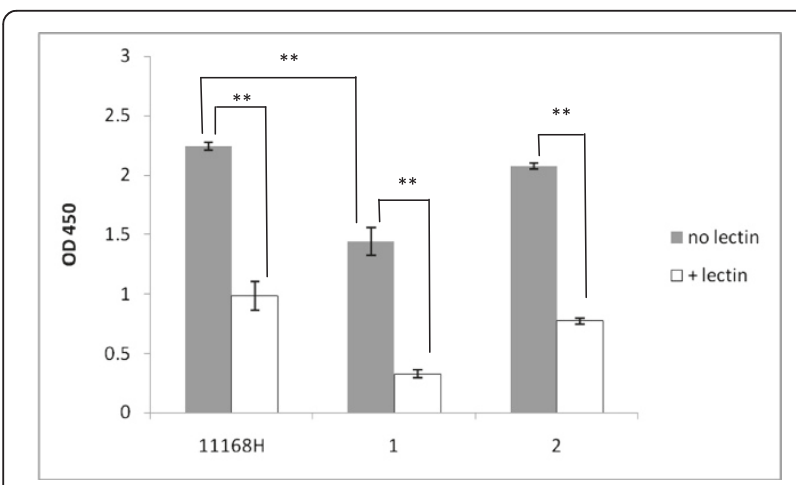

Figure 5 Insertional inactivation of gene peb3 reduced the ability of strain $11168 \mathrm{H}$ to bind immobilised lectin. 1 , recipient (11168H); 2, mutant (11168H/peb3:.:kan r ); 3, complementation

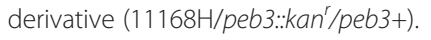

hypothesis we conducted a comparative analysis of the dynamics of $k p s M$ and peb3 gene expression at different growth stages in a liquid culture using real time PCR (RT-PCR). The results showed a dramatic increase in the level of peb3 gene expression at $48 \mathrm{hrs}$ (Figure 6A), whilst there was a reduction in $k p s M$ gene expression after 24 hrs (Figure 6B).

\section{Discussion}

In this study, a model of bacterial attachment was developed. This model is based on monitoring bacterial binding to immobilized analogues of host cell receptor. Although we only tested attachment of Campylobacter jejuni to SBA lectin, the method may have wider application for investigation of interaction of other bacteria with other host cell receptors and their analogues.

The system was successfully tested by using $C$. jejuni strain $11168 \mathrm{H}$ and its isogenic mutant $11168 \mathrm{H} /$ peb3. Using the assay, we investigated interaction of bacteria carrying cell surface located GalNAc residues with immobilised SBA lectin. The binding was found to be specific and dependent on the presence of soluble lectin and GalNAc molecules, and was abolished by bacterial deglycosylation. The study suggests the ability of $C$. jejuni 


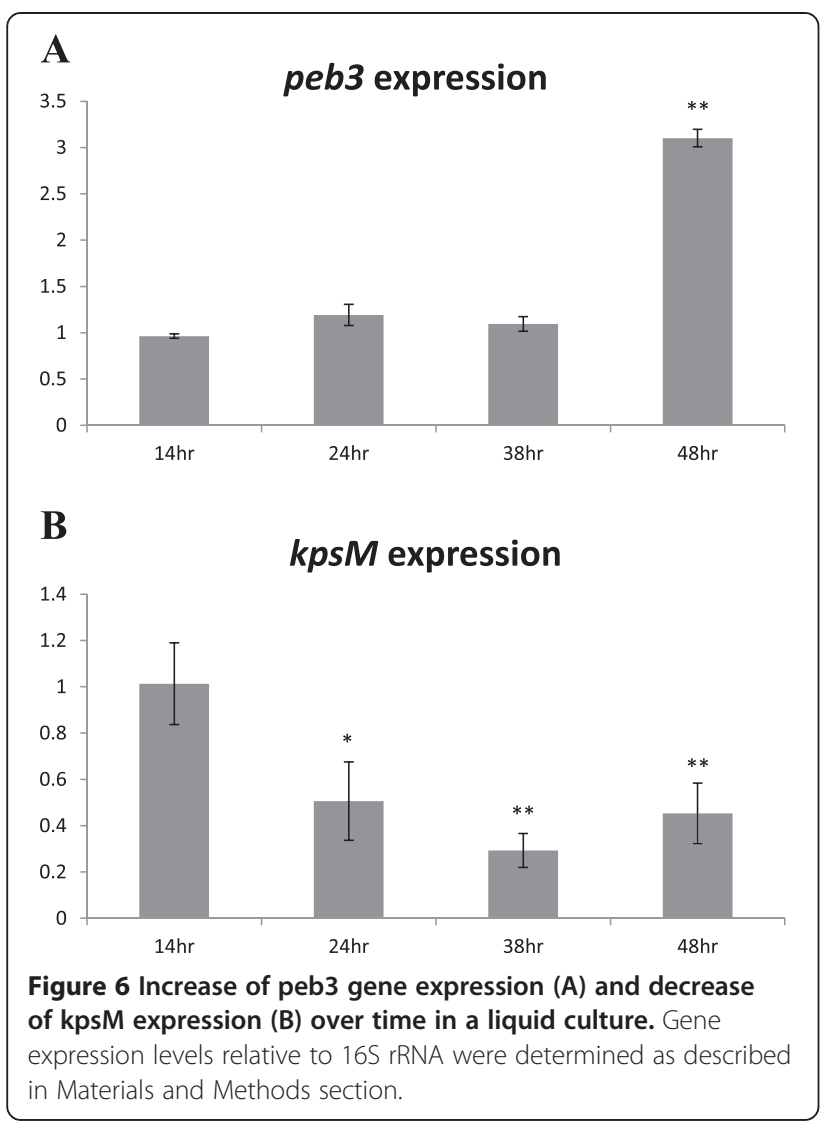

to produce various cell surface GalNAc-containing cell surface structures.

The SBA lectin used in this study shares binding specificity with C-type lectins (including MGL receptors) produced by host cells. According to a recent study, Campylobacter has the ability to interact with MGL receptors expressed on macrophages and dendritic cells (DCs), which may modulate host immune response [13]. Human MGL receptors specifically recognise terminal GalNAc residues [29,30]. Together with other C-type lectins, the MGL receptors may be recognised by viruses, e.g. a filovirus [31]. In addition, it was shown that MGL recognizes a GalNAc containing antigen of a helminth parasite Shistosoma mansoni [32]. Despite some data suggesting a role of MGL receptors as a host defence factor, the role of these molecules in $C$. jejuni infection is not clear. However, there is a possibility that, via interaction with MGL expressing macrophages and DCs this pathogen may subvert host immune response. It was suggested that $C$. jejuni with functional MGL ligand (GalNAc) may decrease IL-6 production by DCs [13].

Campylobacter have been known to produce a number of N-glycoproteins, including PEB3 [33]. However, it was still unclear which glycoprotein is reactive with MGL. Our results demonstrated that peb3 mutation reduces but does not completely eliminate binging, suggesting the presence of other cell surface structures responsible for attachment. Surprisingly, mutation in $j l p A$ gene, encoding another cell surface glycoproptein, had no effect on the ability of $C$. jejuni to bind to the immobilized SBA lectin. According to other studies, $j l p A$ mutation also had no effect on invasion of host cells $[34,35]$.

An isogenic non-capsulated mutant $11168 \mathrm{H} / \mathrm{kpsM}$ showed an increase in binding indicating a negative effect of capsule on bacterial attachment. In addition, results of RT-PCR showed an increase of peb3 and a decrease of $k p s M$ gene expression over time, suggesting that a shielding effect of capsule may be essential at the initial stages of infection, hiding bacterial cell surface structures. Subsequent down regulation of CPS production during colonisation may lead to exposure of other bacterial cell surface structures required for the attachment and/or evasion of host immune response.

\section{Conclusions}

The results of this study demonstrated a complex interplay of Campylobacter capsule and glycoprotein adhesins in pathogen-host interaction. The developed assay will assist in more detailed investigation of such interaction and in the development of inhibitors of attachment as novel antibacterials.

\section{Methods}

\section{Bacterial strains and growth conditions}

C. jejuni strain $11168 \mathrm{H}$ and its isogenic mutant $11168 \mathrm{H} /$ kpsM::kan ${ }^{r}$ were described previously $[19,36]$. C. jejuni was grown under microaerophilic conditions $\left(5 \% \mathrm{O}_{2}\right.$, $10 \% \mathrm{CO}_{2}, 85 \% \mathrm{~N}_{2}$ ) at $37^{\circ} \mathrm{C}$ on Columbia Blood Agar (Oxoid) containing 6\% defibrinated horse blood (Fisher) and Skirrow supplement (Sigma). Antibiotics (chloramphenicol $10 \mu \mathrm{g} / \mathrm{ml}$ and/or kanamycin $50 \mu \mathrm{g} / \mathrm{ml}$ ) were added to the media as required. E. coli strains XL1 and XL2 (Stratagene) were used in cloning experiments. E. coli strains were maintained on Luria-Bertani agar (Oxoid) plates or in Luria-Bertani broth (Oxoid) supplemented with appropriate antibiotics (ampicillin $100 \mu \mathrm{g} / \mathrm{ml}$, kanamycin $50 \mu \mathrm{g} / \mathrm{ml}$ or chloramphenicol $34 \mu \mathrm{g} / \mathrm{ml}$ ) at $37^{\circ} \mathrm{C}$.

\section{General cloning techniques}

Molecular cloning was performed using standard protocols. The plasmids used in this study are listed in Table 1. Restriction enzymes and antarctic phosphatase were purchased from New England Biolabs. T4 DNA ligase and T4 DNA polymerase were purchased from Promega. Oligonucleotides were ordered from Sigma-Genosys. Genomic and plasmid DNAs were extracted using Qiagen kits. Restriction, DNA ligation, dephosphorylation and blunt-ending were performed according to manufacturers' protocols. 
Table 1 Plasmids used in this study

\begin{tabular}{lll}
\hline Plasmids & Description & Source (reference) \\
\hline pGEM-T Easy & Cloning vector & Promega \\
pJMK30 & Source of kan $^{r}$ cassette & {$[37]$} \\
pAV35 & Source of cam $^{r}$ cassette & {$[37]$} \\
pBAD33 & Contains pBAD promoter & {$[38]$} \\
pPGL1 & C. jejuni $16 \mathrm{~kb}$ fragment, & {$[24]$} \\
& containing pg/ gene cluster, & \\
& cloned into pBR322 & \\
pRRC & Cassette cloned into pRR & {$[39]$} \\
& (fragment of rRNA gene cluster & \\
& cloned into pGEM-T easy) & \\
\hline
\end{tabular}

\section{Construction of $C$. jejuni mutants}

Fragments of the genes peb3 and $j l p A$ were PCR amplified using the primers listed in Table 2 and cloned into pGEM-T Easy (Promega) vector to produce plasmids pGEM_peb3 and pGEM_jlpA respectively. In order to disrupt the peb3 gene, the pGEM_peb3 plasmid was digested with PflMI, blunt ended and ligated with the SmaI-digested $\mathrm{kan}^{r}$ cassette producing pGEMpeb3_kan construct. The $j l p A$ gene was disrupted by insertion of the XbaI-digested $\mathrm{cam}^{r}$ cassette (isolated from pAV35, Table 1) into the BsaBI restriction site of pGEM_jlpA plasmid, yielding pGEM_jlpA_cam. In both cases the orientation of the antibiotic resistance cassette was the same as that of the target gene to avoid a negative polar effect in the mutants. Mutagenesis using the constructed derivatives was conducted via electroporation and selection of the derivatives on media supplemented with appropriate antibiotics. Allelic replacement was confirmed by PCR. The mutants were designated $11168 \mathrm{H} / \mathrm{peb3}:: \mathrm{kan}^{r}$ and $11168 \mathrm{H} / j l p A:: \mathrm{cam}^{r}$.

\section{Complementation of peb3 mutant}

Peb3 gene was PCR amplified using primers described in Table 1. The product was digested with XbaI enzyme and cloned into $\mathrm{XbaI}$-digested pRRC plasmid to produce pRRC_peb3. Restriction analysis verified that the gene was transcribed in the same orientation as the $\mathrm{cam}^{r}$ gene. After transformation of the $11168 \mathrm{H} /$ peb3:: $\mathrm{kn}^{r}$ mutant with plasmid pRRC_peb3, $\operatorname{Kan}^{\mathrm{r}} \mathrm{Cam}^{\mathrm{r}}$ clones were selected.
Table 3 Primers used for RT-PCR

\begin{tabular}{lll}
\hline Primer name & Primer sequence (5'-3') & Used for \\
\hline q-16 s-for & ACAGGTGCTGCACGGCTGTC & Control \\
q-16 s-rev & TGCTCGGCCGAACCGTTAGC & Control \\
Peb3_qpcr_for & GCATCGGCTTGATCTTGTGCG & peb3 expression \\
Peb3_qpcr_rev & CGTTGTGCCTGAAGGTGCTGG & peb3 expression \\
kpsM_qpcr_for & GCCTGAGTTCCATTCATAAGCTGGG & kpsM expression \\
kpsM_qpcr_rev & TGGGTAGTTGGGGAGCCTATGAG & kpsM expression \\
\hline
\end{tabular}

PCR analysis confirmed integration of peb3 gene into one of the rRNA gene clusters. The complementation deriva-

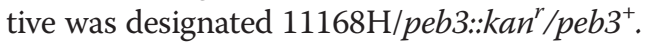

\section{Binding assay}

Bacterial attachment was studied in ELISA-like assay using a 96-well microtiter plate Maxisorp ${ }^{\mathrm{Tm}}$ (Thermo Scientific) coated Soya Bean Agglutinin (SBA) lectin (Sigma) in bicarbonate-coating buffer: $5.3 \mathrm{~g} / \mathrm{L} \mathrm{Na}_{2} \mathrm{CO}_{3}$, $4.2 \mathrm{~g} / \mathrm{L} \mathrm{NaHCO} 3,1 \mathrm{~g} / \mathrm{L}$ sodium azide, $\mathrm{pH}$ 9.6.

Microtiter plate wells were incubated overnight with SBA lectin $(10 \mu \mathrm{g} / \mathrm{ml})$ at $4^{\circ} \mathrm{C}$, followed by blocking with $1 \%$ Bovine Serum Albumin (BSA) overnight at $4^{\circ} \mathrm{C}$. BSAcoated, wells were used as negative control. Bacteria (two-day cultures of $C$. jejuni or one-day cultures of $E$. coli) were harvested, resuspended in Phosphate-Buffered Saline (PBS) to $\mathrm{OD}_{600}=1,0.1 \mathrm{ml}$ suspensions (corresponding to $4 \times 10^{8}$ c.f.u. of $C$. jejuni) were added to each well of the microtiter plate, followed by incubation for $40 \mathrm{~min}$ at room temperature. After rinses with PBS, supplemented with $0.2 \%$ Tween (PBST) the plate was incubated with biotinylated SBA lectin (Vectors Laboratories) for $60 \mathrm{~min}$ at room temperature. The wells were then treated with horseradish peroxidase-conjugated streptavidin (Sigma) for $30 \mathrm{~min}$ at room temperature followed by incubation with TMB (3,3',5,5'-Tetramethylbenzidine) substrate (Sigma) for $10 \mathrm{~min}$. The reaction was stopped by adding stop solution $\left(1 \mathrm{M} \mathrm{H}_{2} \mathrm{SO}_{4}\right)$. Binding was monitored by measuring OD at $450 \mathrm{~nm}$. For inhibition studies, the plates were treated with bacterial suspension in the presence of SBA lectin or GalNAc (Sigma) at different concentrations. Detachment was carried out by addition

Table 2 Primers used for mutation of peb3 and jlpA and for complementation of peb3

\begin{tabular}{lll}
\hline Primer & Sequence (5'-3') & Used for \\
\hline peb3_for & ATGAAAAAATTATTACTTTATTTGGTGCATG & Mutation of peb3 gene \\
peb3_rev & TTATTCTCTCCAGCCGTATTTTTAAAATTTC & Mutation of peb3 gene \\
jlpA_for & ATGAAAAAGGTATTTTCTCTCTATTGG & Mutation of jlpA gene \\
jlpA_rev & TTAAAATGACGCTCCGCCCATTAACATAG & Mutation of jlpA gene \\
peb3_Xbal_for & ATAATCTAGAAAGGAATACTATGAAAAAATTATTACTTATTTGGGC & Complementation of peb3 mutation \\
Peb3_Xbal_rev & AGGTTCTAGATTAATGATGATGATGATGATGTTCTCTCCAGCCGTATTTTTAAAATTTC & Complementation of peb3 mutation \\
\hline
\end{tabular}


to wells with immobilised bacteria of either soluble SBA lectin or GalNAc, followed by incubation for $40 \mathrm{~min}$ at room temperature.

\section{Fluorescein SBA (FSBA) labelling of C. jejuni and E.coli cells}

Fluorescein labelling of cells was done as described previously [40]. FSBA (Vector Laboratories) $(100 \mu \mathrm{g} / \mathrm{ml}$ in PBS) was mixed with an equal volume of bacterial suspension and incubated for $40 \mathrm{~min}$ at room temperature. Bacteria were pelleted, washed twice in PBS to remove any unbound lectin. Samples were observed by fluorescence microscopy using a laser scanning confocal microscope (Leica TCS SP2 AOBS) with a $63 \mathrm{X}$ immersion objective.

\section{Treatment with exo-glycosidase}

In order to remove GalNAc residues bacterial cells were treated with $20 \mathrm{U}$ of $\mathrm{N}$-acetylgalactosaminidase (NEB) for $60 \mathrm{~min}$ at $37^{\circ} \mathrm{C}$ according to manufacturer's protocol.

\section{RNA isolation and RT-PCR}

For RNA isolation, C. jejuni cells were grown for 48 hours under microaerophilic conditions (5\% O2, 10\% $\mathrm{CO} 2,85 \% \mathrm{~N} 2$ ) at $37^{\circ}$ in three separate flasks (biological replicates) in Brain Heart Infusion Broth (Oxoid). Samples for RNA isolation were taken at $14 \mathrm{~h}, 24 \mathrm{~h}, 38 \mathrm{~h}$ and $48 \mathrm{~h}$ intervals. Immediately after taking the samples from the flasks RNAprotect Bacteria Reagent (Qiagen) was added to the cultures to stabilize mRNA. The total RNA from each sample was extracted using the RNeasy Mini Kit (Qiagen). The purified RNA samples were treated with On-Column DNaseDigestion Kit (Qiagen) followed by treatments with DNase in order to remove residual DNA contamination. RNA concentration was estimated using NanoDrop ND-1000 spectrophotometer (NanoVue). The quality and integrity of total RNA was monitored using the Agilent 2100 Bioanalyzer (Agilent Technologies).

RT-PCR was used for gene expression studies of peb3 and $k p s M$ using primers listed in Table 3. Primers were designed from $C$. jejuni DNA sequences using NCBI web server (http://www.ncbi.nlm.nih.gov/tools/primer-blast/). In addition, potential secondary structures and primer dimer formation were verified using an on-line tool, Sigma-Genosys DNA calculator. Primers were purchased from Sigma Genosys Ltd. One-step RT-PCRs were performed in triplicate by using QuantiFast SYBR Green RTPCR Kit (Qiagen). The RT-PCR reaction was performed in a total volume of $12.5 \mu \mathrm{l}$, containing $6.25 \mu \mathrm{l}$ master mix and $0.25 \mathrm{RT}$ mix, consisting of $1 \mu \mathrm{l}$ forward primer, $1 \mu \mathrm{l}$ reverse primer $3.6 \mu \mathrm{l}$ diluted RNA (50 ng) and $6.25 \mu \mathrm{l}$ water. Primers were added to $100 \mu \mathrm{M}$ final concentration. Each sample was analysed in technical duplicates and biological triplicates.
The cycle parameters were as follows: an initial reverse transcription step for $10 \mathrm{~min}$ at $50^{\circ} \mathrm{C}$, and then PCR initial activation step for $5 \mathrm{~min}$ at $95^{\circ} \mathrm{C}$ followed by two-step cycling: denaturation at $95^{\circ} \mathrm{C}$ for $10 \mathrm{~s}$ and combined annealing $60^{\circ} \mathrm{C}$ for $30 \mathrm{sec}$. The number of cycles was 35 . The changes in gene expression ( $n$-fold) calculated from the qRT-PCR data. Analysis of relative gene expression data was done using the $2^{-2 \Delta \Delta C T}$ method as described previously [41]. The $16 \mathrm{~S}$ rRNA was used as the internal controls.

\section{Statistical analysis}

All experiments were repeated a minimum of three times, and data are expressed as mean $\pm \mathrm{SD}$. Differences were considered significant for $\mathrm{P}<0.05$ (", $\mathrm{P}$ value $0.05-0.01$; **, $\mathrm{P}$ value $<0.01$ ). Comparison of two groups was made with an unpaired, two-tailed student's t-test. Comparison of multiple groups was made with ANOVA.

\section{Competing interests}

The authors declared that they have no competing interests.

\section{Authors' contributions}

SR carried out the experiments, analysed the data and was involved in manuscript preparation. AVK conceived and designed the study, was involved in setting up the experiments and data analysis, and prepared the manuscript for submission. AS was involved in coordination and design of the study, and in manuscript preparation. All authors read and approved the final manuscript.

\section{Acknowledgements}

The study was not supported by any external funding.

Received: 14 November 2013 Accepted: 6 May 2014 Published: 31 May 2014

\section{References}

1. Silva J, Leite D, Fernandes M, Mena C, Gibbs PA, Teixeira P: Campylobacter spp. as a Foodborne Pathogen: a review. Front Microbiol 2011, 2:1-12. article number 200.

2. Olson CK, Ethelberg S, van Pelt W, Tauxe RV: Epidemiology of Campylobacter jejuni infections in industrialized nations. In Campylobacter. Edited by Nachamkin I, Szymanski C, Blaser MJ. Washigton, DC, USA: ASM Press; 2008:163-189.

3. Jeon B, Muraoka WT, Zhang Q: Advances in Campylobacter biology and implications for biotechnological applications. Microb Biotechno/ 2010, 3(3):242-258.

4. Nougayrede JP, Fernandes PJ, Donnenberg MS: Adhesion of enteropathogenic Escherichia coli to host cells. Cell Microbiol 2003, 5(6):359-372.

5. Rubinchik S, Karlyshev AV, Seddon A: Molecular mechanisms and biological role of Campylobacter jejuni attachment to host cells. Eur J Microbiol Immunol (Bp) 2012, 2(1):32-40.

6. Magalhaes A, Reis CA: Helicobacter pylori adhesion to gastric epithelial cells is mediated by glycan receptors. Braz J Med Biol Res 2010, 43(7):611-618.

7. Aspholm M, Olfat FO, Norden J, Sonden B, Lundberg C, Sjostrom R, Altraja S, Odenbreit S, Haas R, Wadstrom T, Engstrand L, Semino-Mora C, Liu H, Dubois A, Teneberg S, Arnqvist A, Boren T: SabA is the H. pylori hemagglutinin and is polymorphic in binding to sialylated glycans. PLOS Pathog 2006, 2(10):e110.

8. Tsuji S, Uehori J, Matsumoto M, Suzuki Y, Matsuhisa A, Toyoshima K, Seya T: Human intelectin is a novel soluble lectin that recognizes galactofuranose in carbohydrate chains of bacterial cell wall. J Biol Chem 2001, 276(26):23456-23463. 
9. Day CJ, Tiralongo J, Hartnell RD, Logue CA, Wilson JC, von Itzstein M, Korolik $\checkmark$ : Differential carbohydrate recognition by Campylobacter jejuni strain 11168: influences of temperature and growth conditions. PLOS One 2009, 4(3):e4927.

10. Guerry P, Szymanski CM: Campylobacter sugars sticking out. Trends Microbiol 2008, 16(9):428-435.

11. Szymanski CM, Burr DH, Guerry P: Campylobacter protein glycosylation affects host cell interactions. Infect Immun 2002, 70(4):2242-2244.

12. Karlyshev AV, Everest $P$, Linton D, Cawthraw S, Newell DG, Wren BW: The Campylobacter jejuni general glycosylation system is important for attachment to human epithelial cells and in the colonization of chicks. Microbiology 2004, 150(Pt 6):1957-1964.

13. van Sorge NM, Bleumink NM, van Vliet SJ, Saeland E, van der Pol WL, van Kooyk Y, van Putten JP: N-glycosylated proteins and distinct lipooligosaccharide glycoforms of Campylobacter jejuni target the human C-type lectin receptor MGL. Cell Microbiol 2009, 11(12):1768-1781.

14. Cambi A, Koopman M, Figdor CG: How C-type lectins detect pathogens. Cell Microbiol 2005, 7(4):481-488.

15. Lugo-Villarino G, Hudrisier D, Tanne A, Neyrolles O: C-type lectins with a sweet spot for Mycobacterium tuberculosis. Eur J Microbiol Immunol (Bp) 2011, 1:25-40.

16. Karlyshev AV, Wren BW, Moran AP: Campylobacter Jejuni Capsular Polysaccharide. In Campylobacter. 3rd edition. Edited by Nachamkin I, Szymanski CM, Blaser MJ. Washington, DC, USA: American Society for Microbiology; 2008:505-521.

17. Karlyshev AV, McCrossan MV, Wren BW: Demonstration of polysaccharide capsule in Campylobacter jejuni using electron microscopy. Infect Immun 2001, 69(9):5921-5924.

18. Karlyshev AV, Oyston PC, Williams K, Clark GC, Titball RW, Winzeler EA, Wren BW: Application of high-density array-based signature-tagged mutagenesis to discover novel Yersinia virulence-associated genes. Infect Immun 2001, 69(12):7810-7819.

19. Karlyshev AV, Linton D, Gregson NA, Lastovica AJ, Wren BW: Genetic and biochemical evidence of a Campylobacter jejuni capsular polysaccharide that accounts for Penner serotype specificity. Mol Microbiol 2000, 35:529-541.

20. Bacon DJ, Szymanski CM, Burr DH, Silver RP, Alm RA, Guerry P: A phase-variable capsule is involved in virulence of Campylobacter jejuni 81-176. Mol Microbiol 2001, 40(3):769-777.

21. Bachtiar BM, Coloe PJ, Fry BN: Knockout mutagenesis of the kpsE gene of Campylobacter jejuni 81116 and its involvement in bacterium-host interactions. FEMS Immunol Med Microbiol 2007, 49(1):149-154.

22. Runco LM, Myrczek S, Bliska JB, Thanassi DG: Biogenesis of the fraction 1 capsule and analysis of the ultrastructure of Yersinia pestis. J Bacteriol 2008, 190(9):3381-3385.

23. Deghmane AE, Giorgini D, Larribe M, Alonso JM, Taha MK: Down-regulation of pili and capsule of Neisseria meningitidis upon contact with epithelial cells is mediated by CrgA regulatory protein. Mol Microbiol 2002, 43(6):1555-1564.

24. Fry BN, Korolik V, ten Brinke JA, Pennings MT, Zalm R, Teunis BJ, Coloe PJ, van der Zeijst BA: The lipopolysaccharide biosynthesis locus of Campylobacter jejuni 81116. Microbiology 1998, 144(Pt 8):2049-2061.

25. Pei ZH, Ellison RT 3rd, Blaser MJ: Identification, purification, and characterization of major antigenic proteins of Campylobacter jejuni. J Biol Chem 1991, 266(25):16363-16369.

26. Linton D, Allan E, Karlyshev AV, Cronshaw AD, Wren BW: Identification of $\mathrm{N}$-acetylgalactosamine-containing glycoproteins PEB3 and CgpA in Campylobacter jejuni. Mol Microbiol 2002, 43(2):497-508.

27. Jin S, Joe A, Lynett J, Hani EK, Sherman P, Chan VL: JlpA, a novel surface-exposed lipoprotein specific to Campylobacter jejuni, mediates adherence to host epithelial cells. Mol Microbiol 2001, 39(5):1225-1236.

28. Scott NE, Bogema DR, Connolly AM, Falconer L, Djordjevic SP, Cordwell SJ: Mass spectrometric characterization of the surface-associated $42 \mathrm{kDa}$ lipoprotein JlpA as a glycosylated antigen in strains of Campylobacter jejuni. J Proteome Res 2009, 8(10):4654-4664.

29. Higashi N, Fujioka K, Denda-Nagai K, Hashimoto S, Nagai S, Sato T, Fujita $Y$, Morikawa A, Tsuiji M, Miyata-Takeuchi M, Sano Y, Suzuki N, Yamamoto K, Matsushima K, Irimura T: The macrophage C-type lectin specific for galactose/N-acetylgalactosamine is an endocytic receptor expressed on monocyte-derived immature dendritic cells. J Biol Chem 2002, 277(23):20686-20693.
30. van Vliet SJ, Saeland E, van Kooyk Y: Sweet preferences of MGL: carbohydrate specificity and function. Trends Immunol 2008, 29(2):83-90.

31. Takada A, Fujioka K, Tsuiji M, Morikawa A, Higashi N, Ebihara H, Kobasa D, Feldmann $\mathrm{H}$, Irimura T, Kawaoka Y: Human macrophage C-type lectin specific for galactose and $\mathrm{N}$-acetylgalactosamine promotes filovirus entry. J Virol 2004, 78(6):2943-2947.

32. van Vliet SJ, van Liempt E, Saeland E, Aarnoudse CA, Appelmelk B, Irimura T, Geijtenbeek TBH, Blixt O, Alvarez R, van Die I, van Kooyk Y: Carbohydrate profiling reveals a distinctive role for the C-type lectin MGL in the recognition of helminth parasites and tumor antigens by dendritic cells. Int Immunol 2005, 17(5):661-669.

33. Young NM, Brisson JR, Kelly J, Watson DC, Tessier L, Lanthier PH, Jarrell HC, Cadotte N, St Michael F, Aberg E, Szymanski CM: Structure of the N-linked glycan present on multiple glycoproteins in the Gram-negative bacterium: Campylobacter jejuni. J Biol Chem 2002, 277(45):42530-42539.

34. Novik V, Hofreuter D, Galan JE: Identification of Campylobacter jejuni genes involved in its interaction with epithelial cells. Infect Immun 2010, 78(8):3540-3553.

35. Flanagan RC, Neal-McKinney JM, Dhillon AS, Miller WG, Konkel ME: Examination of Campylobacter jejuni putative adhesins leads to the identification of a new protein, designated FIpA, required for chicken colonization. Infect Immun 2009, 77(6):2399-2407.

36. Karlyshev AV, Wren BW: Detection and initial characterization of novel capsular polysaccharide among diverse Campylobacter jejuni strains using alcian blue dye. J Clin Microbiol 2001, 39(1):279-284.

37. van Vliet $\mathrm{AH}$, Wooldridge $\mathrm{KG}$, Ketley JM: Iron-responsive gene regulation in a Campylobacter jejuni fur mutant. J Bacteriol 1998, 180(20):5291-5298.

38. Guzman LM, Belin D, Carson MJ, Beckwith J: Tight regulation, modulation, and high-hevel expression by vectors containing the arabinose $\mathrm{pBAD}$ promoter. J Bacterio/ 1995, 177(14):4121-4130.

39. Karlyshev AV, Wren B: Development and application of an insertional system for gene delivery and expression in Campylobacter. Appl Environ Microbiol 2005, 71(7):4004-4013.

40. Cole HB, Ezzell JW, Keller KF, Doyle RJ: Differentiation of Bacillus anthracis and other bacillus species by lectins. J Clin Microbio/ 1984, 19(1):48-53.

41. Livak KJ, Schmittgen TD: Analysis of relative gene expression data using real-time quantitative PCR and the 2(T)(-Delta Delta C) method. Methods 2001, 25(4):402-408.

doi:10.1186/1471-2180-14-141

Cite this article as: Rubinchik et al: A negative effect of Campylobacter capsule on bacterial interaction with an analogue of a host cell receptor. BMC Microbiology 2014 14:141.

\section{Submit your next manuscript to BioMed Central and take full advantage of:}

- Convenient online submission

- Thorough peer review

- No space constraints or color figure charges

- Immediate publication on acceptance

- Inclusion in PubMed, CAS, Scopus and Google Scholar

- Research which is freely available for redistribution 